УДК 615.322: 547.9

\title{
ИССЛЕДОВАНИЯ ПО РАЗРАБОТКЕ МЕТОДИКИ СТАНДАРТИЗАЦИИ ЛИСТЬЕВ БОЯРЫШНИКА КРОВАВО-КРАСНОГО
}

\author{
(C) В.А. Куркин", Т.В. Морозова, О.Е. Правдивцева \\ Самарский государственный медицинский университет, ул. Чапаевская, 89, \\ Самара, 443099 (Россия), e-mail: Kurkinvladimir@yandex.ru
}

Боярышник кроваво-красный (Crataegus sanguinea Pall., сем. Розоцветные - Rosaceae) широко распространен на территории Российской Федерации. При этом в медицинской практике нашей страны находят применение только цветки и плоды боярышника в качестве кардиотонических лекарственных средств. Листья боярышника кроваво-красного содержат флавоноиды (гиперозид, рамнозид витексина и др.), аскорбиновую кислоту и дубильные вещества и являются перспективным видом лекарственного растительного сырья. Заготовка листьев является менее трудоемкой в отличие от заготовки цветков и плодов, причем несомненным преимуществом листьев является и длительный период заготовки сырья. Следует отметить, что листья боярышника вместе с цветками находят применение в зарубежной медицине.

Нами разработана методика количественного определения суммы флавоноидов в листьях боярышника кровавокрасного в пересчете на гиперозид. Установлено, что оптимальным экстрагентом для листьев боярышника кроваво-красного является 70\% этиловый спирт. Проведено исследование уровня содержания и динамики накопления суммы флавоноидов в листьях боярышника кроваво-красного в течение вегетационного периода 2015 г. При этом наибольшее содержание фла-

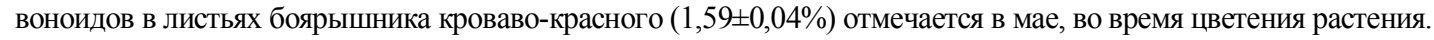

Ключевые слова: род Боярышник, Crataegus L., боярышник кроваво-красный, Crataegus sanguinea Pall., боярышника листья, гиперозид, флавоноиды, спектрофотометрия.

\section{Введение}

Боярышник кроваво-красный (Crataegus sanguinea Pall., сем. розоцветные - Rosaceae) широко pacпространен на территории нашей страны [1]. В настоящее время в медицинской практике Российской Федерации применяются только цветки и плоды боярышника в качестве кардиотонических средств [2-4]. Одним из перспективных видов сырья боярышника являются листья боярышника кроваво-красного [5, 6]. Листья боярышника кроваво-красного имеют сложный химический состав: флавоноиды (гиперозид, рамнозид витексина), аскорбиновую кислоту и дубильные вещества $[4,5,7]$. Создание эффективных импортозамещающих лекарственных препаратов, как правило, начинается с вопросов изучения химического состава лекарственного растительного сырья, а также с разработки методик стандартизации. Ведущей группой биологически активных соединений для плодов и цветков боярышника кроваво-красного являются флавоноиды, среди которых доминирующим компонентом является гиперозид [3, 7]. Следовательно, возможным методом анализа является дифференциальная спектрофотометрия, с применением раствора хлорида алюминия, в пересчете на гиперозид. Аналогичные методики были разработаны ранее для цветков и плодов боярышника на кафедре фармакогнозии с ботаникой и основами фитотерапии СамГМУ $[9,10]$. Методика

Куркин Владимир Александрович - заведующий кафедрой фармакогнозии с ботаникой и основами фитотерапии, профессор, доктор фармацевтических наук, тел. (846) 260-33-59, e-mail: Kurkinvladimir@yandex.ru Морозова Татьяна Владимировна - интерн кафедры фармакогнозии с ботаникой и основами фитотерапии, e-mail: tanyfrost@mail.ru

Правдивцева Ольга Евгеньевна - доцент кафедры фармакогнозии с ботаникой и основами фитотерапии, e-mail: pravdivtheva@mail.ru анализа листьев боярышника была ранее разработана на базе кафедры фармакогнозии с курсом ботаники и основ фитотерапии БГМУ [11]. Она заключается в дифференциальной спектрофотометрии с использованием раствора алюминия хлорида. В соответствии с данной методикой извлечения из сырья получают методом двухкратной экстракции сырья 80\% этиловым спиртом в соот-

\footnotetext{
* Автор, с которым следует вести переписку.
} 
ношении «сырье - экстрагент» - $1: 200$. Расчет содержания действующих веществ производится по сумме флавоноидов в пересчете на рутин. При этом аналитическая длина волны составляет 409 нм. На наш взгляд, данная методика нуждается в существенной оптимизации. Прежде всего, литературные данные и наши предварительные исследования показывают, что в листьях боярышника кроваво-красного доминирующим флавоноидом является гиперозид, имеющий максимум поглощения в присутствии алюминия при 412 нм, как и некоторые другие флавоноиды $[7,12,13]$.

Целью нашего исследования является разработка методики количественного определения флавоноидов в листьях боярышника кроваво-красного.

\section{Экспериментальная часть}

Листья боярышника кроваво-красного для нашего эксперимента были заготовлены на территории Самарской области в течение вегетационного периода 2015 г. Собранное сырье было высушено на воздухе без доступа прямых солнечных лучей. Проводилось исследование зависимости различных параметров экстракции на выход действующих веществ из сырья. Прежде всего, нами изучалось влияние экстрагента на процесс экстракции (табл. 1). При этом спирт этиловый $70 \%$ концентрации был выбран в качестве оптимального экстрагента. Это согласуется с литературными данными для сырья $[7,9,10]$, содержащего флавоноиды, среди которых преобладает гиперозид. При этом следует отметить, что в содержание суммы флавоноидов при использовании спирта этилового в концентрации от 60 до 80\% резких изменений не наблюдается. Видимо, поэтому в некоторых случаях экстрагентом для листьев боярышника выбирают $80 \%$ этиловый спирт [11].

Нами изучен также вопрос относительно продолжительности экстракции на кипящей водяной бане (табл. 2). Результаты исследований по выбору оптимального соотношения «сырье - экстрагент», приведенные в таблице 3 , свидетельствуют о целесообразности использования однократной экстракции в соотношении «сырье - экстрагент» - $1: 50$. Таким образом, определено, что оптимальными параметрами экстракции являются: извлечение $70 \%$ этиловым спиртом на кипящей водяной бане в течение 60 мин в соотношении «сырье - экстрагент» - $1: 50$. Зависимость выхода флавоноидов из листьев боярышника кровавокрасного от степени измельченности сырья представлена в таблице 4. Следует отметить, что, по нашим данным, степень измельчения от 1 до 3 мм сильного влияния на экстракцию не оказывает. Однако нами выбрана степень измельчения 2 мм в качестве оптимальной. Метрологические характеристики методики отражены в таблице 5 . Из нее следует, что ошибка единичного определения составляет $\pm 2,83 \%$.

Таблица 1. Зависимость выхода флавоноидов листьев боярышника кроваво-красного от концентрации экстрагента

\begin{tabular}{c|c}
\hline Экстрагент & $\begin{array}{c}\text { Содержание суммы флавоноидов } \\
\text { в пересчете на а.с.с. и гиперозид, } \%\end{array}$ \\
\hline Вода & $0,72 \pm 0,02$ \\
$40 \%$ этанол & $0,99 \pm 0,03$ \\
$50 \%$ этанол & $1,00 \pm 0,03$ \\
$60 \%$ этанол & $1,10 \pm 0,03$ \\
$70 \%$ этанол & $1,14 \pm 0,03$ \\
$80 \%$ этанол & $1,00 \pm 0,03$ \\
$90 \%$ этанол & $0,98 \pm 0,03$ \\
$96 \%$ этанол & $0,84 \pm 0,02$ \\
\hline
\end{tabular}

Таблица 2. Зависимость выхода флавоноидов листьев боярышника кроваво-красного от времени экстракции на кипящей водяной бане

\begin{tabular}{c|c}
\hline $\begin{array}{c}\text { Время экстракции } \\
\text { на кипящей водяной } \\
\text { бане, мин }\end{array}$ & $\begin{array}{c}\text { Содержание суммы флаво- } \\
\text { ноидов в пересчете на а.с.с. } \\
\text { и гиперозид, \% }\end{array}$ \\
\hline 45 & $1,13 \pm 0,03$ \\
60 & $1,14 \pm 0,03$ \\
90 & $1,07 \pm 0,03$ \\
120 & $1,03 \pm 0,03$ \\
\hline
\end{tabular}

Таблица 3. Зависимость выхода флавоноидов листьев боярышника кроваво-красного от соотношения «сырье-экстрагент»

\begin{tabular}{c|c|c}
\hline $\begin{array}{c}\text { Соотношение } \\
\text { «сырье - экстрагент» }\end{array}$ & $\begin{array}{c}\text { Содержание суммы флавоноидов в пересчете } \\
\text { на а.с.с. и гиперозид, \% }\end{array}$ & $\begin{array}{c}\text { Содержание в суммы флавоноидов в шроте, } \\
\text { в пересчете на а.с.с. и гиперозид, \% }\end{array}$ \\
\hline $1: 30$ & $0,98 \pm 0,02$ & $0,232 \pm 0,01$ \\
$1: 50$ & $1,02 \pm 0,02$ & $0,100 \pm 0,003$ \\
$1: 100$ & $1,03 \pm 0,03$ & $0,100 \pm 0,003$ \\
\hline
\end{tabular}


Таблица 4. Зависимость выхода флавоноидов листьев боярышника кроваво-красного от степени измельченности сырья

\begin{tabular}{c|c}
\hline $\begin{array}{c}\text { Размер } \\
\text { частиц, мм }\end{array}$ & $\begin{array}{c}\text { Содержание суммы флавоноидов } \\
\text { в пересчете на а.с.с. и гиперозид, } \%\end{array}$ \\
\hline 1 & $1,07 \pm 0,03$ \\
2 & $1,08 \pm 0,03$ \\
3 & $1,05 \pm 0,03$ \\
\hline
\end{tabular}

Таблица 5. Метрологические характеристики методики количественного определения суммы флавоноидов в листьях боярышника кроваво-красного

\begin{tabular}{c|c|c|c|c|c|c|c}
\hline $\mathrm{f}$ & $\bar{x}$ & $\mathrm{~S}$ & $\mathrm{~S}^{2}$ & $\mathrm{P}(\%)$ & $\mathrm{T}(\mathrm{P}, \mathrm{t})$ & $\Delta \mathrm{X}$ & $\mathrm{E}, \%$ \\
\hline 10 & 1,20 & 0,1126 & 0,0127 & 95 & 2,23 & 0,03 & $\pm 2,83$ \\
\hline
\end{tabular}

Методика анализа суммы флавоноидов в листьях боярышника. Аналитическую пробу сырья измельчают до размера 2 мм. Около 1 г сырья (точная навеска) измельченного сырья помещают в колбу со шлифом вместимостью 100 мл, прибавляют 50 мл 70\% этилового спирта. Колбу закрывают пробкой и взвешивают на тарирных весах с точностью до $\pm 0,01$. Колбу присоединяют к обратному холодильнику и нагревают на кипящей водяной бане (умеренное кипение) в течение 60 мин. Затем колбу охлаждают в течение 30 минут при комнатной температуре, закрывают той же пробкой, снова взвешивают и восполняют недостающий экстрагент до первоначальной массы. Извлечение фильтруют через рыхлый комочек ваты или фильтр с красной полосой (извлечение из листьев). Испытуемый раствор для анализа флавоноидов готовят следующим образом: 1 мл полученного извлечения помещают в мерную колбу вместимостью 25 мл, прибавляют 1 мл 3\% спиртового раствора алюминия хлорида и доводят объем раствора до метки 70\% этиловым спиртом (испытуемый раствор А). Раствор сравнения готовят следующим образом: 1 мл полученного извлечения помещают в мерную колбу на 25 мл, доводят объем раствора до метки 70\% этиловым спиртом (раствор сравнения А).

Измерение оптической плотности проводят при длине волны 412 нм через 40 мин после приготовления всех растворов. Содержание суммы флавоноидов в пересчете на гиперозид и абсолютно сухое сырье в процентах (Х) вычисляют по формуле:

$$
X=\frac{D \cdot 50 \cdot 25 \cdot 100}{330 \cdot m \cdot 1 \cdot(100-W)}
$$

где $D$ - оптическая плотность испытуемого раствора; 330 - удельный показатель поглощения гиперозида; $m$ - масса сырья, в граммах; $W$ - потеря в массе при высушивании, в процентах.

С использованием разработанной методики были проанализирован ряд образцов листьев боярышника кроваво-красного. При этом было установлено, что содержание суммы флавоноидов в листьях лежит в пределах от $0,89-1,59 \%$.

Целью нашего дальнейшего исследования явилось изучение динамики накопления суммы флавоноидов в листьях боярышника кроваво-красного, заготовленных с одного дерева в течение вегетационного периода 2015 г. Анализ проводился в соответствии с методикой, описанной выше.

Результаты проведенного анализа динамики накопления суммы флавоноидов в листьях боярышника кроваво-красного отражены в таблице 6. Следует отметить, что содержание суммы флавоноидов в листьях боярышника кроваво-красного меняется с течением времени. Наибольшее содержание флавоноидов в ли-


Похожая закономерность, видимо, характерна для листьев и была выявлена ранее для листьев боярышника, несмотря на то, что авторы определяли флавоноиды по другой методике [11]. Несмотря на то, что содержание суммы флавоноидов в листьях боярышника несколько ниже (1,08-1,59\%), чем в цветках боярышника кроваво-красного (1,41-1,84\%), данное сырье представляет интерес с точки зрения потенциального источника БАС $[9,10]$.

Таблица 6. Динамика накопления суммы флавоноидов в листьях боярышника кроваво-красного

\begin{tabular}{c|c|c}
\hline $\begin{array}{c}\text { Месяц сбора } \\
\text { сырья }\end{array}$ & Фенофаза & $\begin{array}{c}\text { Содержание суммы флавоноидов в пересчете на а.с.с. } \\
\text { и гиперозид, \% }\end{array}$ \\
\hline Май & Цветение & $1,59 \pm 0,04$ \\
Июнь & Начало плодоношения & $1,23 \pm 0,03$ \\
Июль & Плодоношение & $1,12 \pm 0,03$ \\
Август & Начало поспевания плодов & $1,10 \pm 0,03$ \\
Сентябрь & Стадия спелости плодов & $1,08 \pm 0,03$ \\
\hline
\end{tabular}




\section{Bыводы}

1. Результаты проведенных нами исследований наглядно свидетельствуют о том, что оптимальным подходом к анализу листьев боярышника кроваво-красного является экстракция в течение 60 мин на кипящей водяной бане, где в качестве экстрагента используется 70\% этиловый спирт в соотношении «сырье экстрагент» $-1: 50$.

2. Оптимальным временем сбора листьев боярышника является период цветения растения - в мае.

3. Листья боярышника кроваво-красного являются перспективным источником новых лекарственных препаратов.

\section{Список литературы}

1. Флора СССР. М.; Л., 1939. Т. ІХ. С. 416-468.

2. Государственная фармакопея СССР. 11 изд. Вып. 2. М., 1990. 400 с.

3. Куркин В.А. Фармакогнозия: учебник для студентов фармацевтических вузов (факультетов). 2-е изд., перераб. и доп. Самара, 2007. 1239 с.

4. Куркин В.А. Основы фитотерапии: учебное пособие. Самара, 2009. 963 с.

5. Хасанова С.Р., Трофимова С.В., Кудашкина Н.В. Определение флавоноидного состава листьев боярышника кроваво-красного из флоры РБ методом ВЭЖХ // Современная медицина и фармацевтика: анализ и перспективы развития: материалы 8 Международной научно-практической конференции. М., 2013. С. 36.

6. Трофимова С.В., Хасанова С.В., Кудашкина Н.В. Изучение антиаритмической активности листьев Crataegus sanguinea (Rosaceae) // Медицинский вестник Башкортостана. 2011. Т. 6, №2. С. 299-302.

7. Растительные ресурсы СССР: Цветковые растения, их химический состав, использование; Семейства Hydrangeaceae - Haloragaceae. Л., 1987. С. $34-42$.

8. Куркина А.В. Новые подходы к стандартизации цветков боярышника // Химия растительного сырья. 2013. №2. С. 171-176.

9. Куркина А.В. Флавоноиды фармакопейных растений: монография. Самара, 2012. 290 с.

10. Трофимова С.В. Фармакогностическое изучение листьев боярышника кроваво-красного Crataegus sanguinea Pall. из флоры Башкортостана: дис. ... канд. фармац. наук. Уфа, 2014. 142 с.

11. Куркин В.А., Дубищев А.В., Куркина А.В. Правдивцева О.Е. Сравнительное фитохимическое исследование сырья двух видов рода Crataegus // Интер-медикал. 2014. №1. С. 90-92.

12. Хисямова Д.М., Куркин В.А. Изучение фенольного состава надземной и подземной части лапчатки прямой // Аспирантский вестник Поволжья. 2015. №3-4. С. 350-352.

Поступило в редакиию 29 апреля 2016 г.

После переработки 19 марта 2017 г. 
Kurkin V.A.", Morozova T.V., Pravdivtseva O.E. STUDIES ON THE DEVELOPMENT OF THE METHODIC OF STANDARDIZATION OF LEAVES OF CRATAEGUS SANGUINEA PALL.

Samara State Medical University, Chapaevskaia st., 89, Samara, 443099 (Russia), e-mail: Kurkinvladimir@yandex.ru

Hawthorn blood-red (Crataegus sanguinea Pall., the family Rosaceae) spreads widely in the Russian Federation. Wherein just flowers and fruits of hawthorn are used as cardiotonic medicines in the medical practice of our country. Hawthorn blood-red leaves are the perspective herbal materials, leaves contain flavonoids ((hyperoside, rhamnoside of vitexin, etc.), ascorbic acid and tannins. The gathering leaves is less time-consuming, unlike the collecting of flowers and fruits, another undoubted advantage of the leaves is long period of gathering raw material. It should be noted that hawthorn leaves together with flowers are used in foreign medicine.

The methodic of quantitative analysis of total flavonoids (calculated on hyperoside) in the Crataegus sanguinea Pall. leaves was carried out. There was determined, that $70 \%$ ethanol is optimal extragent. There were studied the dynamics and the level of accumulation of the total flavonoids in the leaves of hawthorn blood-red, which were collected during growing season 2015. The highest content of flavonoids in the leaves of hawthorn blood-red $(1,59 \pm 0,04 \%)$ has been noted in May during the flowering time.

Keywords: genus Crataegus L., hawthorn, Crataegus sanguinea Pall., hawthorn's leaves, hyperoside, flavonoids, spectrophotometry.

\section{References}

1. Flora SSSR. [Flora of the USSR]. Moscow; Leningrad, 1939, vol. IX, pp. 416-468. (in Russ.).

2. Gosudarstvennaia farmakopeia SSSR: Vyp. 2. Obshchie metody analiza. Lekarstvennoe rastitel'noe syr'e. [State Pharmacopoeia of the USSR: Vol. 2. General methods of analysis. Medicinal plant raw materials]. 11 ed. Moscow, 1990, 400 p. (in Russ.).

3. Kurkin V.A. Farmakognoziia. [Pharmacognosy]. Samara, 2007, 1239 p. (in Russ.).

4. Kurkin V.A. Osnovy fitoterapii. [Fundamentals of phytotherapy]. Samara, 2009, 963 p. (in Russ.).

5. Khasanova S.R., Trofimova S.V., Kudashkina N.V. Sovremennaia meditsina i farmatsevtika: analiz i perspektivy razvitiia: materialy 8 Mezhdunarodnoi nauchno-prakticheskoi konferentsii. [Modern medicine and pharmaceutics: analysis and development prospects: materials of the 8th International Scientific and Practical Conference]. Moscow, 2013, p. 36. (in Russ.).

6. Trofimova S.V., Khasanova S.V., Kudashkina N.V. Meditsinskii vestnik Bashkortostana, 2011, vol. 6, no. 2, pp. $299-302$. (in Russ.).

7. Rastitel'nye resursy SSSR: Tsvetkovye rasteniia, ikh khimicheskii sostav, ispol'zovanie; Semeistva Hydrangeaceae Haloragaceae. [Vegetable resources of the USSR: Flowering plants, their chemical composition, use; Families of Hydrangeaceae - Haloragaceae]. Leningrad, 1987, pp. 34-42. (in Russ.).

8. Kurkina A.V. Khimiia rastitel'nogo syr'ia, 2013, no. 2, pp. 171-176. (in Russ.).

9. Kurkina A.V. Flavonoidy farmakopeinykh rastenii: monografiia. [Flavonoids of pharmacopeia plants: monograph]. Samara, 2012, 290 p. (in Russ.).

10. Trofimova S.V. Farmakognosticheskoe izuchenie list'ev boiaryshnika krovavo-krasnogo Crataegus sanguinea Pall. iz flory Bashkortostana: dis. ... kand. farmats. nauk. [Pharmacognostic study of hawthorn leaves of blood-red Crataegus sanguinea Pall. from the flora of Bashkortostan: the dissertation of the candidate of pharmaceutical sciences]. Ufa, 2014, 142 p. (in Russ.).

11. Kurkin V.A., Dubishchev A.V., Kurkina A.V. Pravdivtseva O.E. Inter-medikal, 2014, no. 1, pp. 90-92. (in Russ.).

12. Khisiamova D.M., Kurkin V.A. Aspirantskii vestnik Povolzh'ia, 2015, no. 3-4, pp. 350-352. (in Russ.).

\footnotetext{
* Corresponding author.
} 

